\title{
The Implementation of Fleet Monitoring System using Mobile based Software
}

\author{
V. Geetha, C.K. Gomathy, Maddu Pavan Manikanta Kiran, Gandikota Rajesh
}

\begin{abstract}
Fleet management is an emerging area in analysis and development nowadays. Large scale Companies, emergency forces must to keep track of their trucks and cars and finding out where the vehicle is at the current timing. Our system includes two mobile applications one for organization head i.e., Smart Fleet and other for the driver of the vehicle (smart driver). This system enables the organization to keep track of their vehicles all the time. This is done by the geolocation of the mobile phone in which smart driver application is installed is shared to the mobile phone in which smart fleet application is installed. Organization head who is having our application installed is able to monitor the vehicles, updating the data.
\end{abstract}

Keywords: Mobile Application; Smart Fleet; Smart Driver; Global Positioning System; Geolocation

\section{INTRODUCTION}

Nowadays all most all organisations are having their own vehicle fleets for their purposes such as travelling on a business or personal, transporting goods, providing cab facilities for staff. The organisations are supposed to keep track of their vehicles and be in contactwith drivers. Every smart phone is capable of getting its own geolocation with the help [1] of satellites available to it. Mobile phones have become the most common and popularly used computers available nowadays. The advantage of GPS is wherever the satellites are visible then the that it will be available all the time in the world. Another main usage of GPS is that GPS receivers are available and currently they are all connected together with other electronic gadgets like mobile phones. Users may include[2] their mobile phones in their daily life because of its chances and very much ease to use. Smart phones are reaching all the person due to its growing. Information.To reach common people ,nowadays peple used Information and Communications Technology.

The paper indicates the usage of of mobile application so that it can enables the organisation to keep in contact with their vehicles and track them time to time. By[3] means of finding

Revised Manuscript Received on April 25, 2020.

* Correspondence Author

Dr.V. Geetha*, Assistant Professor in CSE Department, SCSVMV Deemed to be University

Dr.C.K. Gomathy, Assistant Professor in CSE Department, SCSVMV Deemed to be University

Mr.Maddu Pavan Manikanta Kiran , UG Scholar CSE Department, SCSVMV Deemed to be University

Mr. Gandikota Rajesh, UG Scholar CSE Department, SCSVMV Deemed to be University

(c) The Authors. Published by Blue Eyes Intelligence Engineering and Sciences Publication (BEIESP). This is an open access article under the CC BY-NC-ND license (http://creativecommons.org/licenses/by-nc-nd/4.0/) the capabilities of Geolocation,Smart Driver application gives its live location to the Smart Fleet application.

\section{LITERATURE SURVEY}

Today cell Phones are getting reached by everyone's because of its growing affordability. Smartphones brought about by the nearby manufacturing companies.It can be reached with known brands.

This system is based on mobile application. This system includes two mobile applications installed one in mobile of[4]Organization Head and other in the mobile of the vehicle driver. The application is designed using of the leading mobile application development frameworks, Flutter. This system uses the geolocation[5,6] of the mobile phone to track and share with organization.

The billing procedures are discussed by the operators of GSM and it were studied. compression technique was executed and tthat helped around most[7] of the people and the communication operating cost should not affect the unit's performance..

\section{PROPOSED METHODOLOGY}

A new version of the units are implemented and it is in the phase of prototyping available currently in which the hardware named microcontroller is replaced.It should be replaced by less expensive, It should be more felexible. The communicating processes $\mathrm{p} 1$ and $\mathrm{p} 2$ executed on the new hardware named FGPA.FGPA also implemented with the help of memory sharing. Active Process P1 decodes the message received from the GPS and it will give the information to the people about longitude, latitude, speed, date, and time in memory for all the sample cases. The Seond Process is enabled when the VTU informs with the station. It also downloading the information through the wireless channel for further processing..Numerous vehicles are in the area of coverage, and all are reserving the channel with the base station. A priority based model is executed in the station to find which process should start downloading and which process should wait. The second Process P2, after getting the essential data,it communicates the number of points have done the transmission,that are likely to be compared with those getting by the base station. suppose they did not match each other, the unit is downloading all the missing information repeatedly. Once it is successful, Process P2 will be getting stopped and Process P1 takes over all the needed information and waits for the vehicle to move from the starting location so that it has to save the starting locations at the predetermined rate of sampling.

Published By:

Blue Eyes Intelligence Engineering \& Sciences Publication

(C) Copyright: All rights reserved. 


\section{TECHNOLOGIES USED}

The technologies used are Global Positioning System, Flutter, Firebase.

Global Positioning System-- The Global Positioning System (GPS), originally NAVSTAR GPS, is a satellite-based radionavigation system.

It is maily owned by the government of US.GPS is mainly activated by the US Space. It is one of the global navigation satellite systems (GNSS) that provides the GPS receiver about the geolocation and time information near the Earth It does not need any information about the user to transmit any type of information, and it also operates separately of any telephonic or internet reception, so these kind of technologies can enhance the usage of the GPS positioning information mainly. It provides the critical information to the people of military, civil engineers, and commercial users all over the world. The government of US created the proper system, and maintains it regularly, and also helps the user to makes it freely accessible to anyone with a GPS receiver.

Flutter-- The version 1 of Flutter was known as "Sky" and it will be executed on the Android os.It was the developer summit, with the stated intent of being able to render consistently.It is afree ware $\underline{\text { UI software }}$ development kit .It is created by Google. It is used to develop applications for Android, iOS, Windows, Mac, Linux, Google Fuchsiaand the web. During the keynote of Google Developer

Firebase-Firebase is a development platform developed by firebase in 2011. Now it is acquired by the Google. Firebase platform has many services used by developers around the World. The services used in this application are:

- Firebase Authentication

Firebase Authentication service is used to authenticate users.

- Cloud Firestore

Cloud Firestore allows users to store data in any format.

- Firebase Realtime Database

Firebase Realtime Database is a real-time database and back-end service.

\section{V.SYSTEM ARCHITECTURE}

The mobile application is composed of two systems. The first is the mobile application which can used by the organization. Registration is a requirement when using the application.

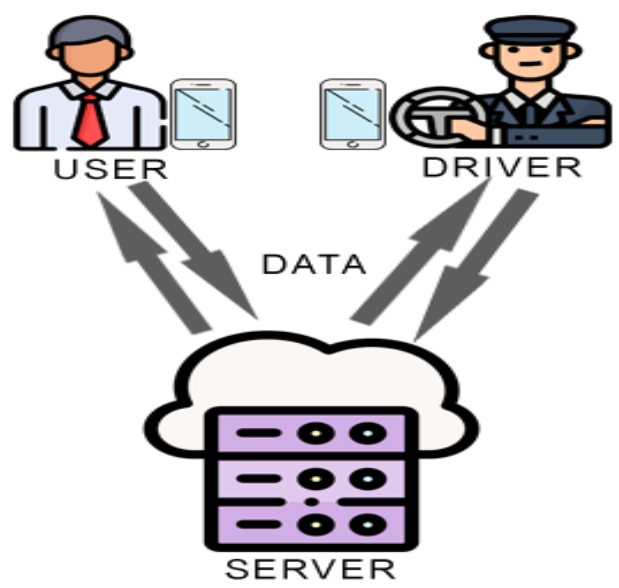

Fig 1: System Architecture
The basic personal information of the user will be stored in a database can be accessed by the organization head. The driver's mobile location will be shared to the system. The second part of the system is the mobile application which is used by the driver.

\section{WORKING PROCEDURES AND RESULTS}

Functionalities of both the applications are always related in one or mode ways. This system has many functionalities namely

- Smart Fleet

oUser Registration

oUser Login

oCreating Drivers

$\circ$ Creating Routes

oCreating Vehicles

o Assigning Driver and Route

oTracking

Each of these functionalities are having their own importance in the whole system working.

Smart Fleet

- User Registration-The person who is responsible for the fleet management of a particular organization will have to install and register on this application.

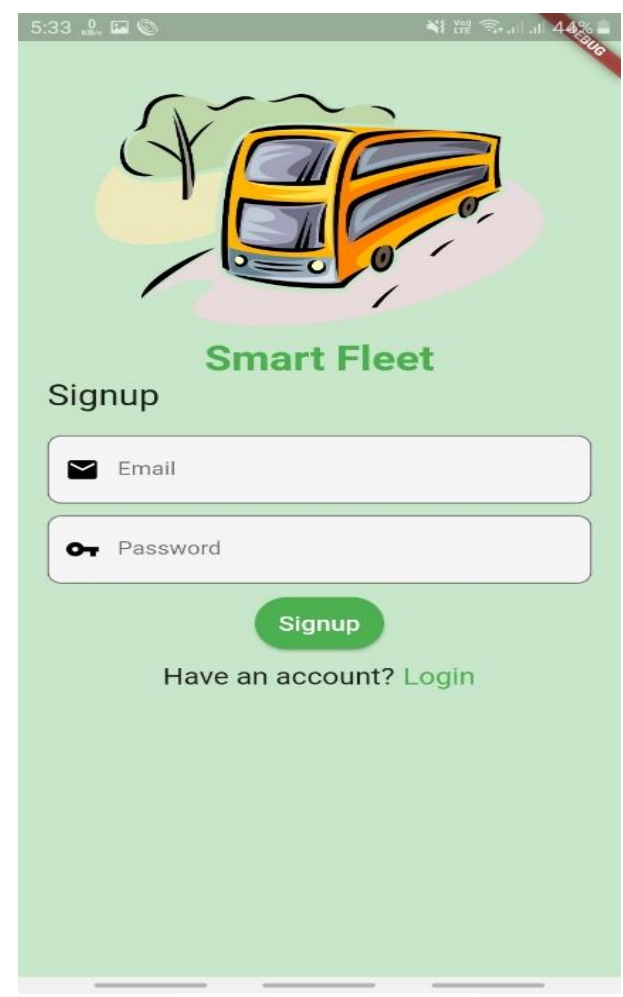

Fig 2:Signup Screen

- User Login-The user who is having an account and has registered previously can login using his/her own credentials. 


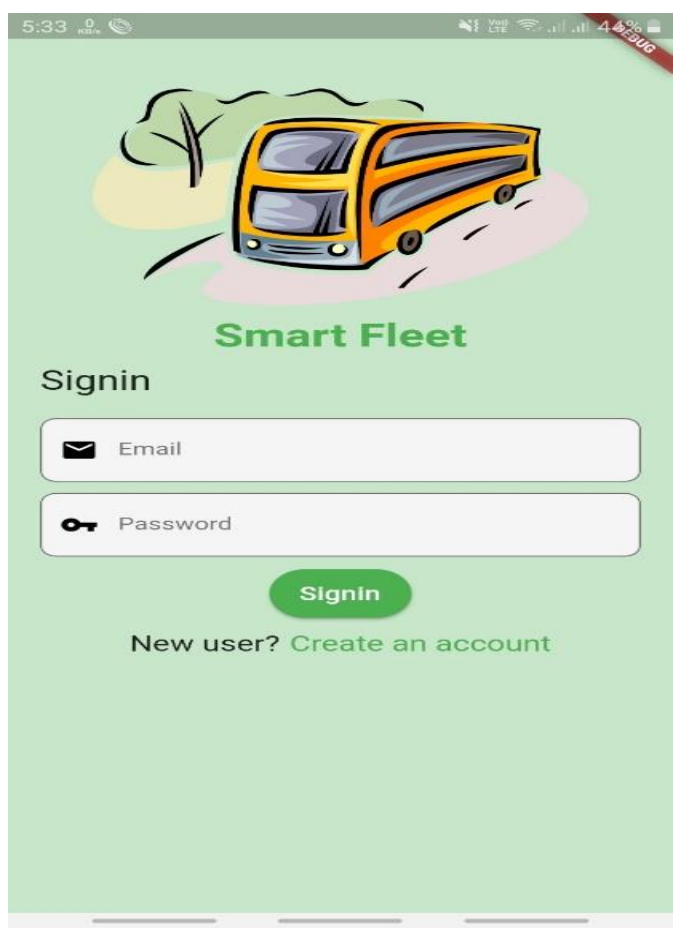

Fig 3:Login Screen

- Creating Drivers-The user can create add drivers using the + button at the top of the driver list page. The user have to fill the driver details in the modal popup shown.

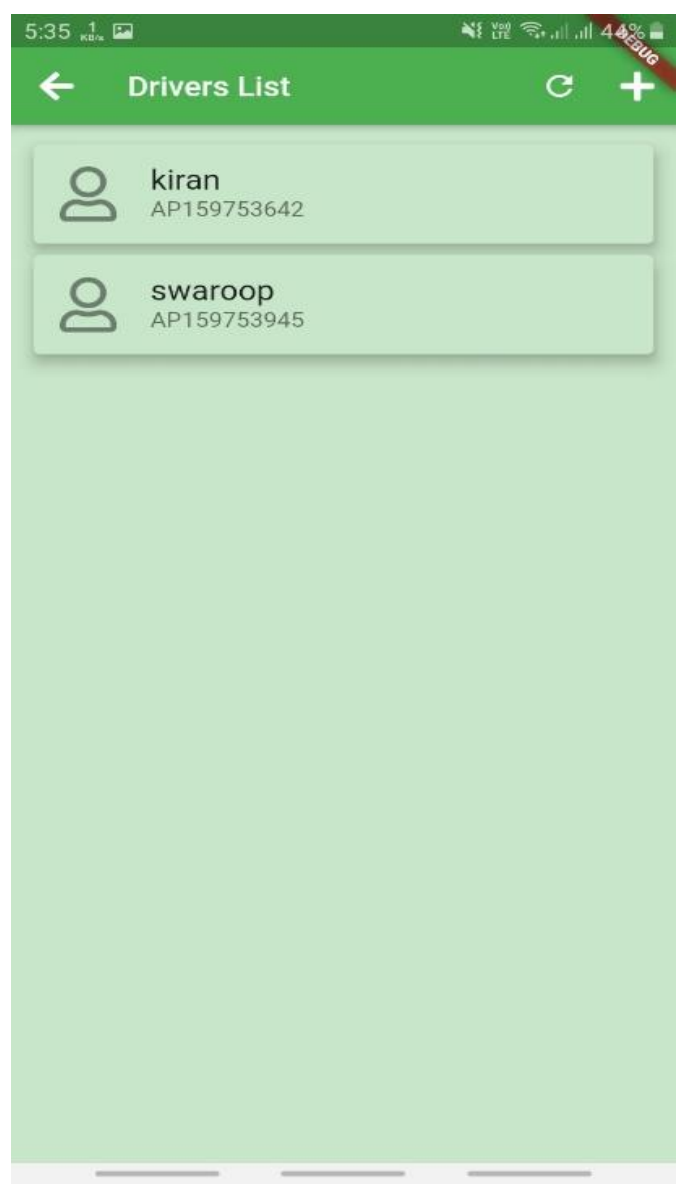

Fig 4: Driver List Screen

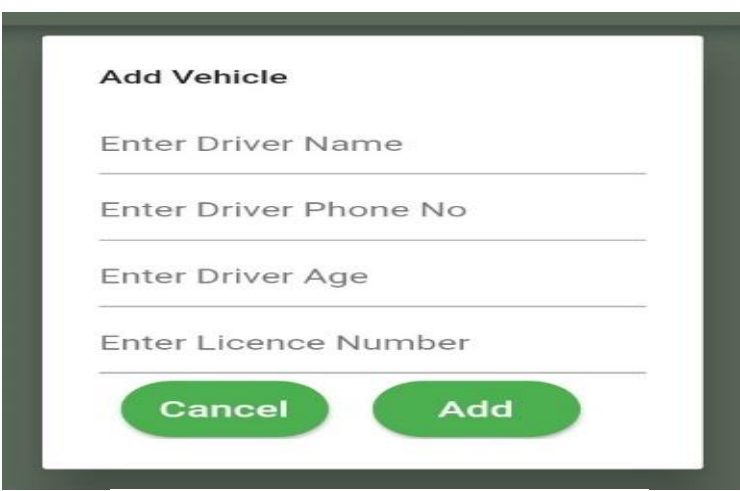

Fig 5: Adding Driver Modal

- Creating Vehicle-The user has the add all the vehicles of the particular organization in to the application using + button at the top left of the Vehicle List Screen.

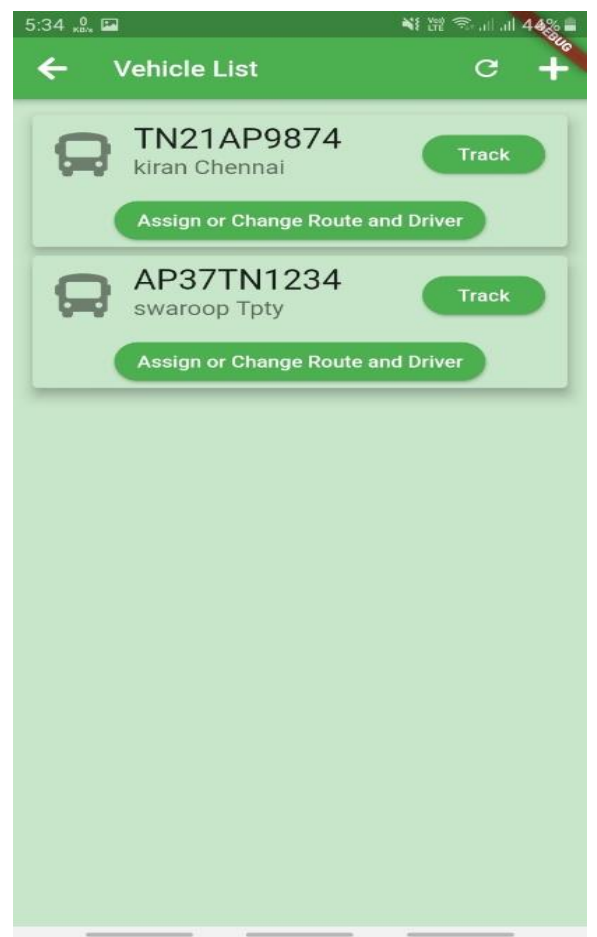

Fig 6 : Vehicle Screen

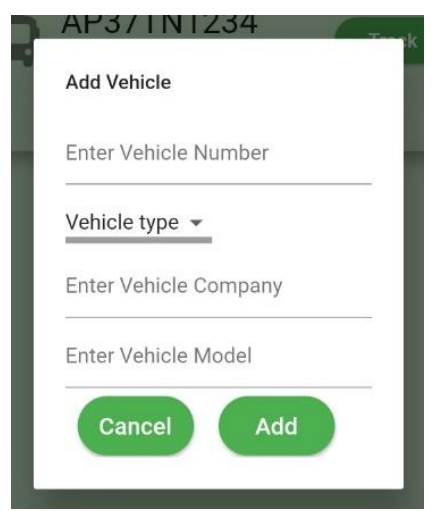

Fig 7: Adding Vehicle Model

- Adding Routes - The user adds the routes in which their vehicles will travel will be added to the application using the add icon button at the top left of the route list screen.

Published By:

Blue Eyes Intelligence Engineering \& Sciences Publication

(C) Copyright: All rights reserved.

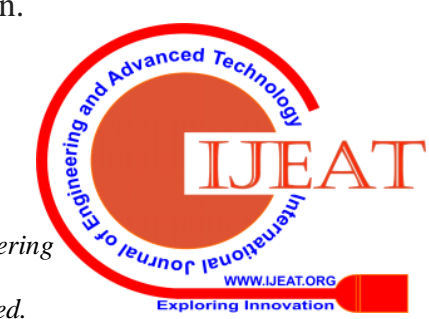


The Implementation of Fleet Monitoring System using Mobile based Software

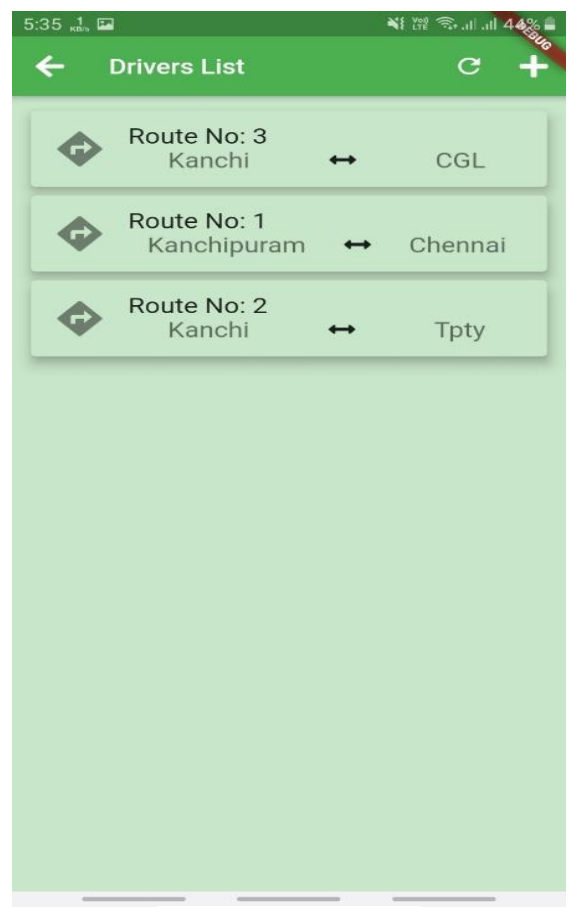

Fig 8 :Routes List

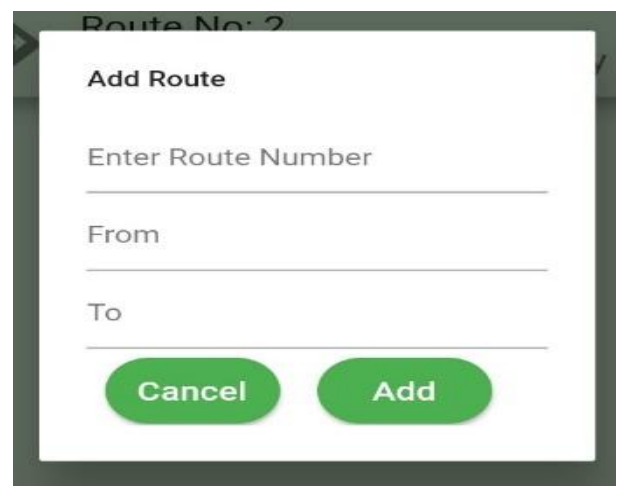

Fig 9:Adding Route Modal

- Assigning the driver and routes-The user has to assign a vehicle with particular driver and route. This can be done by clicking the assign driver and route button in the driver list.

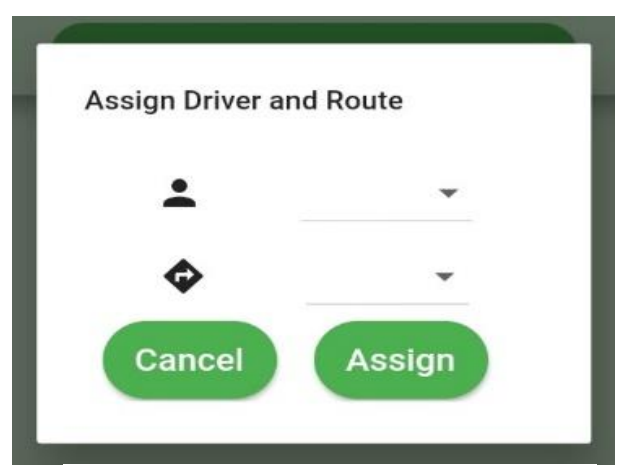

Fig 10: Assigning Driver And Route

- Tracking-The user can track the live location of the vehicle. The particular vehicle that has the track button which is clicked is tracked.

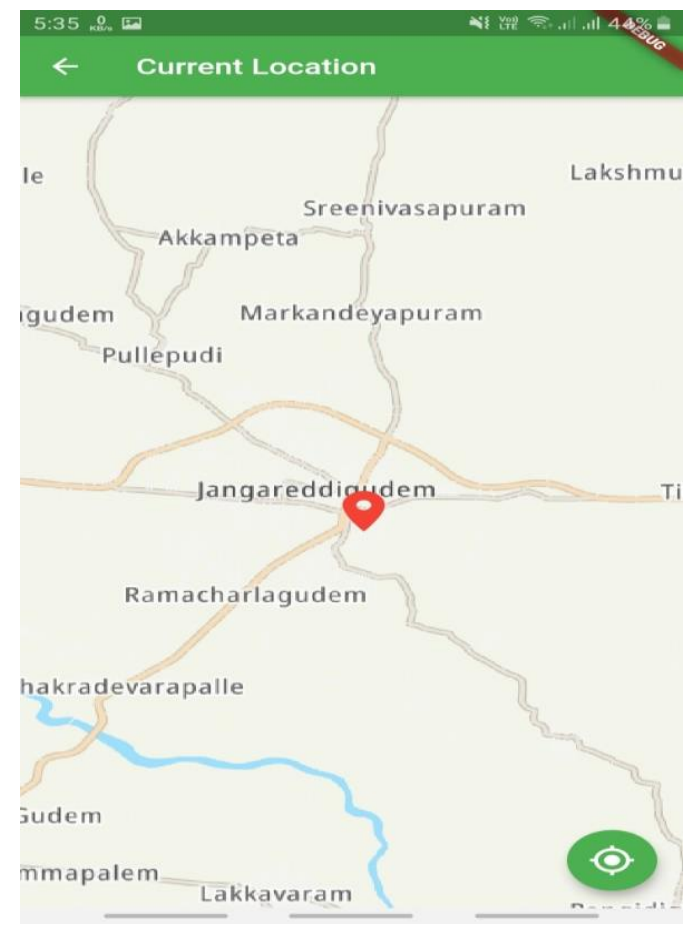

Fig 11: Live Tracking Screen

\section{CONCLUSION}

The movement of college buses is affected by different uncertain conditions due to traffic conjuction. So with the help of fleet monitoring system using mobile based software.The real-time tracking of the bus can be done by our proposed system and this information is then given to a remote user who wants to know the real-time bus information. In this paper, this system is being used in the management of fleet task operations, it has the capability to plan the route for delivery and pickup vehicles. It also in monitoring the rental vehicles. Attaching an LCD is used to enable the development of vehicle guidance model. Research is carried out to embed the mapping system in the memory and it shows the benefits from the fact of the base station.

\section{REFERENCES}

1. Ziad A. Osman, Mazen Jrab, Souleiman Midani,N. Zantout, Implementation of a System for Offline Tracking using GPS", Mediterranean Microwave Symposium 2003, Ain Shams University, Cairo, Egypt, May 6-8 2003 [1] "Understanding GPS: Principles and Applications", Elliott D. Kaplan (Editor), Artech House Telecommunications Library, 1996

2. N.B. Hounsell, B.P. Shrestha, F.N. McLeod, S. Palmer, T. Bowen and J.R. +Head, "Using global positioning system for bus priority in London: traffic signals close to bus stops", 13th World Congress on Intelligent Transport Systems and Services, Vol. 1, No. 2, June 2007.

3. Vishwas Raj Jain, Ravi Bagree, Aman Kumar, Prabhat Ranjan, "wildCENSE: GPS based Animal Tracking System," ISSNIP 2008.

4. Ziad A. Osman, MazenJrab, SouleimanMidani, Rached N. Zantout, "Implementation of a System for Offline Tracking using GPS", Mediterranean Microwave Symposium 2003, Ain Shams University, Cairo, Egypt, May 6-8 2003.

5. C K Gomathy and V Geetha. Article: A Real Time Analysis of Service based using Mobile Phone Controlled Vehicle using DTMF for Accident Prevention. International Journal of Computer Applications 138(2):11-13, March 2016. Published by Foundation of Computer Science (FCS), NY, USA,ISSN No: 0975-8887

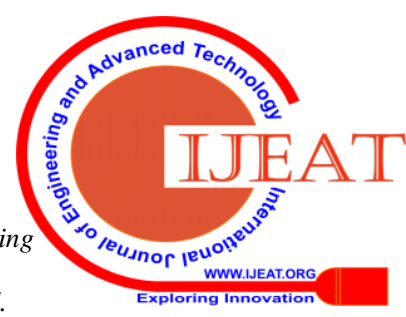


6. C K Gomathy and V Geetha. Article: Evaluation on Ethernet based Passive Optical Network Service Enhancement through Splitting of Architecture. International Journal of Computer Applications 138(2):14-17, March 2016. Published by Foundation of Computer Science (FCS), NY, USA, ISSN No: 0975-8887

7. Dr.C.K.Gomathy, K. Bindhu sravya , P. Swetha , S.Chandrika Article: A Location Based Value Prediction for Quality of Web Service, Published by International Journal of Advanced Engineering Research and Science (IJAERS), Vol-3, Issue-4 , April- 2016] ISSN: 2349-6495

8. DR.C.K.Gomathy , V.Geetha , S.Madhumitha , S.Sangeetha R.Vishnupriya Article: A Secure With Efficient Data Transaction In Cloud Service, Published by International Journal of Advanced Research in Computer Engineering \& Technology (IJARCET) Volume 5 Issue 4, March 2016, ISSN: 2278 - 1323.

9. C.K.Gomathy.(2010),"Cloud Computing: Business Management for Effective Service Oriented Architecture" International Journal of Power Control Signal and Computation (IJPCSC), Volume 1, Issue IV, Oct - Dec 2010, P.No:22-27, ISSN: 0976-268X

\section{AUTHORS PROFILE}

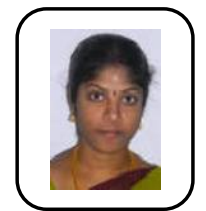

Dr.V.Geetha is assistant professor in computer science and engineering at Sri Chandrasekharendra SaraswathiViswa Mahavidyalaya ,Enathur,Kanchipuram,India. Her area of intrest lies in Java Programming,Software Quality Assurance,Computer System Architecture Domain.

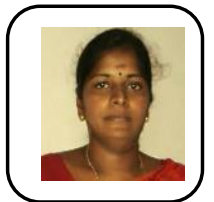

Dr.C.K.Gomathy is assistant professor in computer science and engineering at Sri Chandrasekharendra SaraswathiViswa Mahavidyalaya

,Enathur,Kanchipuram,India. Her area of intrest lies in Software Engineering,Web Services, KnowledgeManagement Domain.

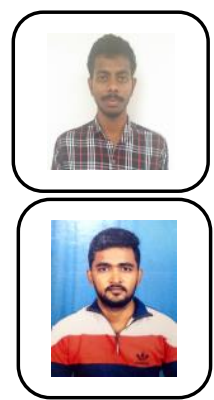

Maddu Pavan Manikanta Kiran, UG Scholar,, B.E. Computer Science and Engineering, SCSVMV.

Gandikota Rajesh, UG Scholar, B.E. Computer Science and Engineering, SCSVMV. 